\title{
CHOP and R-CHOP Therapeutic Responses in Non- Hodgkin Lymphoma Patients in Dr. Soetomo General Hospital Surabaya
}

\author{
Rina Syarifah Salma ${ }^{1}$, S. Ugroseno Yudho Bintoro², Made Putra Sedana ${ }^{2 *}$ \\ ${ }^{1}$ Faculty of Medicine, Universitas Airlangga, Surabaya, Indonesia \\ ${ }^{2}$ Department of Internal Medicine, Faculty of Medicine, Universitas Airlangga - Dr. Soetomo General Hospital, Surabaya, \\ Indonesia
}

\author{
A R T I C L E I N F O \\ Article history: \\ Received 1 August 2018 \\ Received in revised form 10 \\ September 2018 \\ Accepted 24 September 2018 \\ Available online 30 November \\ 2018 \\ Keywords: \\ Lymphoma Non-Hodgkin, \\ CHOP regimen, \\ $\mathrm{R}-\mathrm{CHOP}$ regimen, \\ Response of Therapy. \\ *) Corresponding author: \\ made_putrasedana@yahoo.com
}

\begin{abstract}
A B S T R A C T
Introduction: Non-Hodgkin Lymphoma (NHL) is a group of lymphoid-derived malignant disease with heterogenic biological and clinical manifestations. For over 30 years, CHOP (Cyclophosphamide, Doxorubicin, Vincristine, and Prednisone) has been the first choice of chemotherapy for aggressive NHL. Later in 1997 Rituximab as anti-CD20 monoclonal antibody was introduced and then combined with CHOP as R-CHOP. The objective of this study is to acknowledge the response of the CHOP and R-CHOP therapy in Non-Hodgkin Lymphoma patients at Dr. Soetomo General Hospital.

Methods: The design of this study was retrospective observational study using secondary data obtained from patient's medical records from 2011 to 2015 . The data selected from the medical records are the result of the therapy, as well as patient's gender and age.

Results: The results of patients' therapy were classified into four categories: The study showed that $51.28 \%$ patients had Complete Response, followed by Partial Response (28.21\%), Progressive Disease (17.95\%), and No Change (2.56\%). Sample characteristics showed male patients in higher percentage $(66.67 \%)$, and the majority of patients' age between 51-60 years old (30.77\%). The use of CHOP and R-CHOP regiment were $76.92 \%$ and $20,52 \%$ respectively.

Conclusion: Most of the patients had a complete response. The CHOP regiment is more commonly used in patients compared to R-CHOP.
\end{abstract}

\section{Introduction}

Non-Hodgkin Lymphoma (NHL) is a group of malignant tumors consisting of various subtype. NHL is derived from abnormalities in B-cell and T-cell lymphocytes that shows various clinical and pathological manifestations. ${ }^{1}$ The definite etiology of NHL is not clearly understood, but there are risk factors including immunological status, oncogenic viral infection, carcinogenic substances exposure, and familial. ${ }^{2,3}$

Currently, NHL, Hodgkin lymphoma and leukemia are the sixth most common malignancies in Indonesia. ${ }^{4}$ According to Global Cancer Society, the prevalence of NHL in Southeast Asia is 6.1 cases among men and 3.9 cases among women per 100,000 population with age standardization. ${ }^{5} \mathrm{NHL}$ prevalence continues to increase dramatically over the past few decades, and interests many researchers. There was a stable increase in lymphoma prevalence per 100,000 population based on the age, around 11.1 cases in 1976, then 19.0 cases in 2000, and became 22.7 cases in 2008 which made NHL one of the most important malignancy contributing to increased prevalence of malignancy in general. ${ }^{1,5}$

For over thirty years, CHOP have become the first choice of high-intensity chemotherapy used in aggressive NHL therapy. ${ }^{6,7}$ Rituximab was introduced as an antiCD20 monoclonal antibody in 1997. Rituximab has been proven to be safe and can be used for aggressive NHL therapy combined with standard chemotherapy. The

Biomolecular and Health Science Journal

Available at https://e-journal.unair.ac.id/BHSJ ; DOI: 10.20473/bhsj.v1i2.9244 
combination of Rituximab with $\mathrm{CHOP}$ is known as R$\mathrm{CHOP}^{7,8}$

CHOP and R-CHOP therapeutic responses in NHL patients in Dr. Soetomo General Hospital Surabaya has not been studied before. This study aims to determine the response of $\mathrm{CHOP}$ and $\mathrm{R}-\mathrm{CHOP}$ therapy in NonHodgkin Lymphoma patients in Dr. Soetomo General Hospital Surabaya, as NHL currently becomes one of the most common malignancy in Indonesia.

\section{Methods}

This study was an observational retrospective to determine the response of CHOP and R-CHOP therapy in Non-Hodgkin Lymphoma patients (NHL) in Dr. Soetomo General Hospital. The response rate of therapy was determined by collecting data from the sample examination, including the size of the tumor and the absence of liver and spleen enlargement after CHOP and R-CHOP therapy. All treatment written in medical records.

The sample in this study was Non-Hodgkin Lymphoma patients treated at Oncology Outpatient Clinic Dr. Soetomo General Hospital period of 20112015. The inclusion criteria were NHL patients treated with CHOP or R-CHOP and the availability of the therapeutic response data. While the exclusion criteria were NHL patients treated with CHOP or R-CHOP and drop out.

The variables in this study were gender, age, and therapeutic responses. The data was collected from the patient's medical records. Researchers conducted the study during August to October 2015 by selecting the medical records of NHL patients which met the inclusion criteria.

In this study, evaluation was conducted 21 days after the second cycle of therapy to see the therapeutic responses and determine the appropriate dose. The tumor size was measured in a metric scale (centimeter) before and after therapy with the same instrument. The therapeutic responses were classified into four categories: 1.) Complete Response (CR) if no tumors found, 2.) Partial Response (PR) if there was $\geq 50 \%$ reduction in tumor size compared to its initial size, 3.) No Change (NC) if there was $<50 \%$ reduction in tumor size and no $>25 \%$ enlargement compared to its initial size, 4.) Progressive Disease (PD) if there was $\geq 25 \%$ enlargement in tumor size, or new tumor found. The collected data was processed and presented descriptively.

\section{Results}

In this study, there were 192 NHL patients treated at Oncology Outpatint Clinic Dr.Soetomo General Hospital Surabaya during 2011-2015. From the population, there were 39 NHL patients who met the inclusion criteria, that was NHL patients on CHOP or R-CHOP therapy whose therapeutic responses were classified into $C R, P R$,
NC, or PD. The characteristics of the patients are shown in table 1 below.

Table 1. Characteristics of NHL patients at Oncology Outpatient Clinic Dr. Soetomo General Hospital

\begin{tabular}{ccc}
\hline \multicolumn{3}{c}{ Characteristics } \\
\hline Sex & $\mathbf{n}$ & $\mathbf{( \% )}$ \\
\hline Male & 26 & $66.67 \%$ \\
Female & 13 & $33.33 \%$ \\
\hline Age & $\mathbf{n}$ & $\mathbf{( \% )}$ \\
\hline$<40$ years & 8 & $20.51 \%$ \\
40-50 years & 10 & $25.64 \%$ \\
$51-60$ years & 12 & $30.77 \%$ \\
$>60$ years & 9 & $23.08 \%$ \\
\hline Therapy & $\mathbf{n}$ & $\mathbf{( \% )}$ \\
\hline CHOP & 31 & $79.48 \%$ \\
R-CHOP & 8 & $20.52 \%$ \\
\hline Therapeutic & $\mathbf{n}$ & $(\boldsymbol{\%})$ \\
responses & & $51.28 \%$ \\
\hline CR & 20 & $28.21 \%$ \\
PR & 11 & $2.56 \%$ \\
NC & 1 & $17.95 \%$ \\
PD & 7 &
\end{tabular}

In this study, there were more male patients than female patients participated (66.67\%). Most of the patients was diagnosed at the age of 51-60 years $(30.77 \%)$ with a median age of 52 years. The youngest was 18 years old and the oldest was 69 years old. The CHOP chemotherapy was used more frequently than RCHOP (79.48\%). In this study, total patients with complete response were $51.28 \%$, partial response were $28.21 \%$, no change were $2.56 \%$, and progressive disease were $17.95 \%$

The therapeutic responses of NHL patients are shown in table 2. Patients with CHOP chemotherapy showed more complete response than those with R-CHOP chemotherapy for $54.83 \%$ and $37.50 \%$ respectively. Patients with R-CHOP chemotherapy were more likely to show partial response than those with CHOP therapy, for $37.50 \%$ and $25.80 \%$ respectively. Patients with no change -response were only found in CHOP chemotherapy. Patients with R-CHOP chemotherapy were more likely to show progressive disease response than those with CHOP chemotherapy, for $25 \%$ and $16.13 \%$ respectively.

Table 2. Comparison between the therapeutic responses and therapy used in NHL patients at Oncology Outpatient Clinic Dr. Soetomo General Hospital

\begin{tabular}{lcccc}
\hline \multirow{2}{*}{$\begin{array}{c}\text { Therapeutic } \\
\text { responses }\end{array}$} & \multicolumn{2}{c}{ CHOP } & \multicolumn{2}{c}{ R-CHOP } \\
\cline { 2 - 5 } & $\mathbf{n}$ & $\mathbf{( \% )}$ & $\mathbf{n}$ & $\mathbf{( \% )}$ \\
\hline CR & 17 & $54.83 \%$ & 3 & $37.50 \%$ \\
PR & 8 & $25.80 \%$ & 3 & $37.50 \%$ \\
NC & 1 & $3.24 \%$ & 0 & $0.00 \%$ \\
PD & 5 & $16.13 \%$ & 2 & $25.00 \%$ \\
\hline
\end{tabular}


Based on gender, female patients showed more complete response than male for $69.23 \%$ and $42.30 \%$ respectively. Male patients showed more partial response than female, for $30.76 \%$ and $23.07 \%$ respectively. No change response was found only in male patients $(3.84 \%)$, and progressive disease was more common in male patients than female patients, for $23.10 \%$ and $7.70 \%$ respectively. The details are shown in table 3 .

Table 3. Comparison between the therapeutic response and sex of the patients with NHL at Oncology Outpatient Clinic Dr. Soetomo General Hospital

\begin{tabular}{llllc}
\hline \multirow{2}{*}{$\begin{array}{c}\text { Therapeutic } \\
\text { responses }\end{array}$} & \multicolumn{2}{c}{ Male } & \multicolumn{2}{c}{ Female } \\
\cline { 2 - 5 } & $\mathbf{n}$ & $\mathbf{( \% )}$ & $\mathbf{n}$ & $\mathbf{( \% )}$ \\
\hline CR & 11 & $42.30 \%$ & 9 & $69.23 \%$ \\
PR & 8 & $30.76 \%$ & 3 & $23.07 \%$ \\
NC & 1 & $3.84 \%$ & 0 & $0.00 \%$ \\
PD & 6 & $23.10 \%$ & 1 & $7.70 \%$ \\
\hline
\end{tabular}

\section{Discussion}

Patients with CHOP chemotherapy provided more complete responses than R-CHOP. In this study, CHOP therapy was used more frequently than R-CHOP chemotherapy (79.48\%). Study in Mexico reported that NHL patients treated with R-CHOP chemotherapy did not show significant difference of Overall Survival (OS) compared with CHOP chemotherapy. This was allegedly influenced by the individual condition, such as the advanced staging of tumor when diagnose was determined, thus, it had poor prognosis. Besides that, the other influential factors were poor immunological status and irregular treatment.

Study in Germany, Austria and Switzerland during 1986 and 2012 also reported that the male: female ratio was 2.7: 1 for all types of NHL. ${ }^{9}$ Male predominance occurred in almost all NHL subtypes. According to Global Cancer Statistics, NHL prevalence in Southeast Asia was 6.1 cases in men and 3.9 cases in women per 100,000 population with age standardization. 5,10 The number of male and female patients in this study who showed complete response was $55.00 \%$ and $45.00 \%$ sequentially. When the therapeutic response was compared between male and female, complete response in female was higher $(69.23 \%)$ than male $(42.30 \%)$. A Study conducted in the UK showed that 5 years survival rate in NHL was better in female $(47.00 \%)$ than male $(43.00 \%) .^{11}$

Study in Israel mentioned that there were mechanisms affecting the development of NHL disease in female through the direct effect of estrogen in all types of lymphocytes that express estrogen receptor. A study showed the evidence of estrogen's anti-proliferative effect on lymphoid cells via estrogen $\beta$ receptor $(\mathrm{ER} \beta),{ }^{12}$ and female showed a better therapeutic response to RCHOP chemotherapy than male. The data were collected from 985 patients on R-CHOP chemotherapy who participated in the study. The results showed that female had significantly better Progression-Free Survival (PFS) and better Overall Survival (OS) trends. ${ }^{13}$

The youngest patient in this study was 18 years old and the oldest was 69 years old with a median age of 52 years. A study in Connecticut found that the increase of the age was associated with the time of the diagnosis was first made, which was started from 51 years of all sexes to 65 years for male and 68 years for female. ${ }^{14}$ The incidence of total lymphoid neoplasms increased with age in all races and subgroups. ${ }^{15}$ In Indonesia, the incidence of NHL increases simultaneously with the age.

In this study, the complete response was mostly achieved by patients at the age of 51-60 years (40.00\%). Patients who showed complete response at the age of $>60$ years was $35.00 \%$. Study in the United States, Britain and Canada showed that older age was associated with a lower cure rate. It found that age was associated with a lower cure rate, ranging from 60 to 70 years. Other studies in Ireland failed to prove age as a prognostic factor that had a negative impact on patients. Study in Nebraska, USA, complete response levels in patients $>60$ years old were not significantly different from patients <60 years old; a five-year difference in life expectancy was not associated with lymphoma or its treatment. ${ }^{16}$

In general, the cure rate of hematological diseases in all countries in Europe decreases as the older the patients, both male and female. ${ }^{17,} 18$ There were different literatures determining the age regarding "old". The minimum value varied from 60 years, 65 years, and 70 years. ${ }^{19}$ Study in the United States, patients with older age showed poorer therapeutic response due to poor complete response and more recurrences. The age itself is not an absolute parameter to determine the recovery. Older patients had other diseases that may affect their Status Performance (PS) and physiological disability, cause the inability to tolerate intensive chemotherapy treatment. $^{16}$

The limitation of this study is that not all medical records of NHL patients informed therapeutic response data so that not all patients with NHL could participate in the study. The study also did not include data of the NHL stage of the patient at the first treatment and the NHL subtype, so it cannot describe the population in general.

\section{Conclusion}

The CHOP regiment is more commonly used in patients compared to R-CHOP and most patient had Complete Response (CR) from CHOP or R-CHOP therapy to NonHodgkin's Lymphoma (51.28\%).

\section{Conflict of Interest}

The authors stated there is no conflict of interest. 


\section{References}

1. Little R and Wilson W. Non-Hodgkin Lymphomas. Bethesda Handbook of Clinical Hematology. Philadephia: Lippincott Williams \& Wilkins, 2013, p. 275-6.

2. Clarke $\mathrm{C}$ and Glaser S. Changing Incidence of Non-Hodgkin Lymphomas in the United States. Cancer. 2002; 94: 2015-23.

3. Provan D, Singer R, Baglin T and Dokal I. Lymphoma. Oxford: Oxford University Press, 2004.

4. PHOMIP. Penatalaksanaan Limfoma Non-Hodgkin. PERHOMPEDIN. Jakarta: PERHOMPEDIN, 2010.

5. Skrabek P, Turner D and Seftel M. Epidemiology of Non-Hodgkin Lymphoma. Transfus Apher Sci. 2013; 49: 133-8.

6. Mulyono A, Putra Sedana M and Ashariati A. Asosiasi Ca-125 dengan Respon Terapi pada Penderita Limfoma Non-Hodgkin Agresif yang Mendapat Kemoterapi Cyclophosphamide, Doxorubicin, Vincristine, Prednisone (CHOP). J Intern Med. 2011; 12.

7. Hegele V, Stoll P, Wust D and et a. Pharmaceutical Follow-Up for Patients on Rituximab Therapy for Non-Hodgkin Lymphoma: What Is the Evidence? Int J Clin Pharm. 2013; 35: 513-9.

8. Van Oers M, Klasa R, Marcus R and et a. Rituximab Maintenance Improves Clinical Outcome of Relapsed/Resistant Follicular NonHodgkin Lymphoma in Patients Both with and without Rituximab During Induction: Results of A Prospective Randomized Phase 3 Intergroup Trial. Blood. 2006; 108.

9. Horesh N and Horowitz N. Does Gender Matter in Non-Hodgkin Lymphoma? Differences in Epidemiology, Clinical Behavior, and Therapy. Rambam Maimonides Medical Journal. 2014; 5.

10. Jemal A, Bray F, Center M, Ferlay J, Ward E and Forman D. Global Cancer Statistics. CA: a cancer journal for clinicians. 2011; 61: 69-90.

11. Micheli A, Mariotto A, Giorgi Rossi A, Gatta G and Muti P. The Prognostic Role of Gender in Survival of Adult Cancer Patients. Eur J Cancer. 1998; 34: 2271-8.

12. Yakimchuk K, Hasni M, Guan J, Chao M, Sander B and Okret S. Inhibition of Lymphoma Vascularization and Dissemination by Estrogen Receptor $\beta$ Agonists. Blood. 2014; 123: 2054-61.

13. Sarkozy C, Mounier N, Delmer A, et al. Impact of BMI and Gender on Outcomes in DLBCL Patients Treated with R-CHOP: A Pooled Study from the LYSA. The Lymphoma Study Association. 2014: 112.

14. Zheng T, Mayne S, Boyle P, Holford T, Liu W and Flannery J. Epidemiology of Non-Hodgkin Lymphoma in Connecticut. Cancer. 1992; 70: 840-9.

15. Morton L, Wang S, Devesa S, Hartge P, Weisenburger D and Linet M. Lymphoma Incidence Patterns by WHO Subtype in the United States, 1992-2001. Blood. 2006; 107: 265-76.

16. Nicolaides C, Dimou S and Pavlidisa N. Prognostic Factors in Aggressive Non-Hodgkin's Lymphomas. Oncologist. 1998; 3: 18997.

17. Carli P, Coebergh J and Verdecchia A. Variation in Survival of Adult Patients with Haematological Malignancies in Europe since 1978. Eur J Cancer. 1998; 34: 2253-63.

18. Vercelli M, Capocaccia R, Quaglia A, Casella C, Puppo A and Coebergh J. Relative Survival in Elderly European Cancer Patients: Evidence for Health Care Inequalities. Crit Rev Oncol Hematol 2000; 35: 161-79.

19. Maartense E, Kluin-Nelemans H, le Cessie S, Kluin P, Snijder S and Noordijk E. Different Age Limits for Elderly Patients with Indolent and Agressive Non-Hodgkin Lymphoma and the Role of Relative Survival with Increasing Age. Cancer. 2000; 89: 2667-76. 